\title{
Technical Advancements and Utilization of Spine Surgery

\author{
-International Disparities in Trend-Dynamics \\ Between Japan, Korea, and the USA
}

\author{
Phyo KIM, Ryu KUROKAWA, and Kazushige ITOKI \\ Neurologic Surgery, Dokkyo University School of Medicine, Tochigi
}

\begin{abstract}
Spine surgery has made radical advancements in the last two decades and provision has expanded a great deal. The history of the technical development is briefly reviewed. To analyze trends in utilization and to assess the macroeconomic demand for spine surgery, the incidence of all spine surgery per capita is estimated referring to diverse statistical data from the USA, Korea and Japan. When compared internationally, there is a great disparity in the utilization of spine surgery, especially for fusion/instrumentation. Medico-socioeconomic conditions underlying the variations are discussed. Adequate surgeon training has to be supplied in a matched volume, and the number of surgeons to balance the need is estimated.
\end{abstract}

Key words: fusion techniques, imaging modalities, spine surgery rate, reimbursement, demand/supply balance

\section{Introduction}

It is fair to state that spine surgery has transformed most among the various arenas of neurosurgical practices, perhaps along with endovascular treatments and stereotactic functional neuro-modulations. The 1990s were a period of outburst in technical innovations for spinal surgery. Progress of imaging techniques, with the advent of magnetic resonance imaging (MRI) and multi-detector computed tomography (CT) contributed significantly in the advancement of diagnosis and pinpointing the pathophysiology causing the ailment. The other major fulcrum of the outburst in spine surgery was the development of instrumentation techniques. As the effectiveness of the fixation procedure to secure stability is enhanced, hospital stay is shortened, and together with the advances in the sensitivity and accuracy in the diagnosis, utilization of spine surgery has increased dramatically, ${ }^{22,24,71)}$ especially for degenerative spine diseases which have very high incidence and prevalence. ${ }^{12,39,41,55,69)}$ Further, restitutive surgery, which optimizes use of the muscle, skeletal, and fascial reconstruction and to restore stability, physiological motion and alignment, is emerging as a possible alternative to rigid fixations using metal instrumentations. ${ }^{45}$

The present review encompasses the concise history of the technical developments and trends in the utilization of spine surgery. Provision of spine surgery in countries is assessed, and total utilization is estimated as inferred from various sources of statistical data. ${ }^{17,22,23,32,71,72)}$

\section{Technical Advancements in the Past Two Decades}

\section{Progress of imaging techniques}

The advent of high magnetic field $\mathrm{MRI}^{6,31,66)}$ and multi-detector CT with capability of helical or spiral scanning, ${ }^{14)}$ and subsequent development of computer processing of the data such as multiplanar reconstructions (MPR) or maximum intensity projections, ${ }^{25,36,40,59)}$ enhanced enormously the amount and the availability of information we obtain from neuroimaging studies. This has provided hitherto unavailable insights regarding the pathological processes taking place inside the spinal cord and the nerve roots. Pathologies taking place in the areas previously called the 'hidden zone' surrounded by three-dimensionally complex bony structures and ligaments can be evaluated non-invasively. ${ }^{25,36)}$ High magnetic field MRI (1.5 T to $3 \mathrm{~T}$ ) and new pulse sequences ${ }^{47,61)}$ and image processing based on three-dimensional (3D) sampling allow better delineation of the roots or radiculomedullary vasculature in addition to the cord. ${ }^{6,40,57)}$ These imaging techniques are immediately applicable to daily practices. MPR can show the nerve root outside the common dural sac. It is most useful when the image is obtained in the coronal plane. When taken in a 3D sampling, the MPR can show the cross sectional shape of the neural structures along any curved line which can be set arbitrarily. It is useful for delineation of impingement of the nerve roots. ${ }^{25,36,59)}$ Diffusion tensor imaging (fiber tracking), MR spectroscopy with and without mapping, and functional MRI are all 
being tried in the spinal cord, but we still have to wait for further development of the applications to become useful in our practices. ${ }^{50,53,54)}$

\section{Instrumentation}

Various instruments such as wire-cable systems, ${ }^{15}$ ) rods and frames, ${ }^{35,51)}$ plates and screws, ${ }^{67)}$ pedicle screws, ${ }^{64,74)}$ and interbody cages ${ }^{63)}$ have been devised and used. For the cervical spine and the cranio-cervical junctions, techniques and instruments such as C2 odontoid screw fixation, ${ }^{13)}$ C1-C2 transarticular screws, ${ }^{29,43,52)}$ pedicle screws, ${ }^{2,30,33)}$ lateral mass screws, ${ }^{19,68)}$ anterior cervical plates and screws, ${ }^{4,16,37)}$ and cages $^{38)}$ have been developed and used. Development of what is called the universal spine instrumentation system, which consists of pedicle screws, hooks and rods and rigid locking mechanisms allowing three dimensional degree of freedom in connecting angles, has made fixation easy and reliable. Examples of the early systems include C-D, ${ }^{20)}$ Texas Scottish Rite Hospital ${ }^{44)}$ and others, ${ }^{5)}$ and there has been explosive commercial developments following these pioneers, with various characteristics built in with the intention for ease of use and sturdier fixation. Systems aimed at specific use in the cervical spine or in the cranio-vertebral junction since have been made. When integrated with navigational capabilities, ${ }^{46,65)}$ precise orientation and placement of screws in the vicinity of critical vascular and neuronal structures are facilitated. Transarticular screw fixation of C1-C2,52) or pedicle screw fixation of the cervical spine ${ }^{2,33,46)}$ are examples of the areas where navigation technology has contributed most for safety in the spine. Artificial disk or arthroplasty ${ }^{27,28,49)}$ is another arena of instrumentation with the idea to preserve motion between the spinal segments, and recently has been a center of interest. Its long-term efficacy and advantage over preexisting technologies are yet to be established..$^{7,8,11,76)}$

\section{Trend-Dynamics of Utilization of Instrumentation/Fusion}

As the result of the technical development and widened indications, spinal surgery has increased greatly in supply volume in the past two decades. ${ }^{71)}$ Trend analysis of the curve actually demonstrates close chronological correlation with the advent and release of metallic instruments. ${ }^{22)}$ When compared cross-sectionally between various reference regions in the US, high utilization of instrumentation/fixation is correlated with higher incidence of non-fusion surgery as well. ${ }^{71}$ When compared internationally between the US, Korea, and Japan, higher incidence of instrumental fixation is correlated with higher utilization rate of the all spine surgery.

In US Medicare, spine surgery has been performed in a frequency of 3.9 per 1000 enrollees, and by categories, the distribution is 2.1 for L-discectomy or laminectomy, 1.1 for L-fusion, 0.24 for cervical discectomy or laminectomy, and 0.47 for $\mathrm{C}$-fusions. The ratio of cervical to lumbar spine procedures was 0.22 to $1 .^{71)}$ Spending for lumbar fusion has increased $500 \%$ over the period of 1992 to 2003 from $\$ 75$ million to $\$ 482$ million, and as a proportion of all spine surgery, from $14 \%$ to $47 \%$ of the total spending.

In the US, numbers of fusion surgery increased stepwise, and even more when use of the interbody cages was approved for use in lumbar spine surgery in 1996, resulting in $220 \%$ increments of lumbar spine surgery over the decade. ${ }^{22}$ The advent of the instrument has made interbody fusion from the posterior approach in conjunction with use of pedicle screw fixation very popular. Unlike the preexisting methods of posterolateral fusion, which relied on the bony graft (typically taken from the iliac crest) laid over the exposed and decorticated transverse processes, posterior lumbar interbody fusion (PLIF) uses cages with bone grafts packed inside the disk space and involves exposure limited to between the facets. ${ }^{10,18)}$ Compression force exerted on the cage and bone grafts with pedicle screw/rod system induces better fusion rate. ${ }^{3,58,70)}$ In fact, the use of the cages revitalized the PLIF procedure, replacing the preexisting method which had been performed with bone grafts in the disk space. ${ }^{63)}$ The progress has been furthered with transforaminal lumbar interbody fusion (TLIF), ${ }^{34)}$ in which the facet joint of the symptomatic side is removed totally and the cage is inserted from lateral to the roots, thus avoiding the risks of injury to the cauda equina contained in the common dural sac. ${ }^{21)}$ Stability is provided by the pedicle screw together with the cage.

The progress in the technique and the instruments made the procedure more reliable, so that after a certain amount of training, it can be reproduced in the hands of many general neurosurgeons in community practice. PLIF or TLIF have penetrated very rapidly, all the more because of favorable reimbursement as compared to simple decompression and more involvement with the commercial/industrial sectors. In fact, the average Medicare hospital charges for simple fusion surgery (one or two disk levels, single approach) were $\$ 58,511$ as opposed to $\$ 23,724$ for decompression, and $\$ 80,888$ for complex fusion (more than 2 disk levels or combined anterior and posterior approaches). ${ }^{24)}$ Fusion with instrumentation has become a de facto standard for common lumbar lesions such as disk disease or stenosis which do not involve instability normally. The market for spinal instruments and devices is more than 2 billion a year and has been growing $18 \%$ to $20 \%$ per year. ${ }^{56)}$

In the US, there has been a sharp increase in fixation performed for herniated disks. As many as $63 \%$ of lumbar fusions were performed for disks, $20 \%$ for 
stenosis, and only $20 \%$ in conjunction with spondylolisthesis or spondylolysis, ${ }^{22)}$ the authentic indication for fusion/instrumentation. This constitutes a quite unprecedented pattern of utilization for the fusion procedure. As many as $26 \%$ of stenosis cases, $70 \%$ of degenerative disc disease cases, and $93 \%$ of lysis or listhesis cases undergo fusion with instrumentation. ${ }^{22)}$ In 2007, 33\% of Medicare operations performed for lumbar stenosis involved fusion and $14.3 \%$ employed complex fusion. ${ }^{23)}$ Instrumentation/fixation has been utilized for indications other than the instability of the segments, but no evidence for improved outcome for fusion surgery over non-fusion decompression surgery has been presented. ${ }^{24)}$

\section{Disparity in Utilization and Emerging Criticism}

Among US hospital reference regions, there are marked variations in the per capita utilization of lumbar discectomies and laminectomies, and the disparity is more than 20 fold for spinal fusion procedures. ${ }^{71)}$ It is not correlated with the supply of orthopedic and neurosurgeons, and the incidence of fusion is rather moderate in the states or in the hospital reference regions where the accessibility to medical/surgical services is superior. When closely observing the distribution of the lumbar fusion surgery and non-fusion surgery, there is a visible correlation. One study showed significant variability between spine surgeons in their judgment of surgical indications, especially regarding election of fusion vs non-fusion, and choice of implants on simulated cases. ${ }^{42)}$

General perceptions in the public regarding the inconsistency and disparity, with these epidemiological data, have lead to open criticisms and reports casting suspicions as to the authenticities of spine surgery, especially spine fusions, both within the medical communities and within the general public. ${ }^{1,9,24,62,72,73)}$

\section{Estimation of Demand for Spine Surgery}

Incidence of lumber spine fusion surgery in the USA nationwide was 122,000 in $2001,{ }^{22}$ which corresponds to $61 / 100,000$ adults. The rate was calculated based on the database of the Healthcare Cost and Utilization Project, and varies with different age class. It was 90/100,000 adults for age 60 years and older, and 75 for age 40-59 years, and 30 for age 20-39 years, with $46.1 \%$ in the age higher than 60 years group. The numbers give a rough estimate of the age distribution of spine surgery, and together with US census data, helps to extrapolate the Medicare spinal surgery rate to the entire age groups and thus to assess the incidence of spine surgery in the national general population. When calculated in this manner, the nationwide spine surgery annual rate is $1,800 /$ million general population (Table 1).

For the entire US, estimates of L-spine surgery including ambulatory surgery data can also be obtained from the Healthcare Cost and Utilization Project (HCUP) of the Agency for Healthcare Research and Quality. ${ }^{32)}$ Community Hospitals' Data on inpatient discharges are sent to the HCUP, and the State Inpatient Databases (SIDs) are produced. Each year, a $20 \%$ weighted sample is extracted from the SIDs and used to generate the HCUP's Nationwide Inpatient Sample (NIS). Several states submit similar data on ambulatory surgery to the HCUP, which produces the State Ambulatory Surgery Databases (SASDs). Based on the NIS and SASD data, the incidence of L-spine surgery in the US was estimated to be 2.009 (inpatient: 1.62, outpatient: 0.38 ) per 1,000 adults (age $>20$ years, 2000). ${ }^{32)}$ When adjusted to the US census age distribution, the incidence is 156/100,000 population (assuming no incidence below age 20 years). Applying the cervical to lumbar ratio of 0.22 to $1^{71)}$ and adding the number for cervical spine surgery to the lumbar surgery rate, the estimate of total spine surgery incidence is approximately 2,000 per million population per year.

In 2001, in Medicare, 4.47 inpatient and outpatient spine surgery procedures were performed per 1,000 enrollees. ${ }^{32)}$ Adjusting to the age composi-

Table 1 Utilization and supply of spine surgery in US, Japan, and Korea

\begin{tabular}{lllccc}
\hline & Health care system & Surgeon income & $\begin{array}{c}\text { Incidence of spinal surgery } \\
\text { (n/milion general population/yr) }\end{array}$ & $\begin{array}{c}\text { Number of spine } \\
\text { surgeons }\end{array}$ & $\begin{array}{c}\text { Load per } \\
\text { neurosurgeon/yr }\end{array}$ \\
\hline USA & mixed & output based & $1,800-2,050$ & $20,000 ?$ & $121^{*}$ \\
Japan & national insurance & salary based & $400-725$ & $1,400 ?$ & $65^{* *}$ \\
Korea & national insurance & salary based & 1,630 & 977 & $82^{* * *}$ \\
\hline
\end{tabular}

${ }^{*}$ In US, total numbers of orthopedic surgeons and neurosurgeons is 18,000 and 3,000. Based on the spine surgery rate $(2,000 / m i l-$ lion/yr) and US population (280 million), total number of spine surgery is estimated to be 560,000. Assuming neurosurgeon is performing $65 \%$ of spine surgery as has been reported in Medicare, and all of $3000+$ active members of AANS are engaged in spine surgery, case load per neurosurgeon is estimated to be 121 per year. ${ }^{* *} 193$ surgeons were certified for neuro-spine subspecialty, and 1200 are certified for orthopedic spine (2006). Assuming $13000+$ cases are operated in the NS community, the work load per neurosurgeon would be 65 cases per year. ${ }^{* * *}$ In Korea, there are 980 surgeons specializing in Spine, 520 in NS and 450 in orthopedics. Eighty thousand of spine surgery was performed in 2005 and the load per surgeon would be 82 per year. 
tion of the US census and the spine surgery age distribution, the rate converts to an incidence of 2,050 spine procedures per year per million national population (Table 1).

These numbers which the author has generated referring to three independent sets of US data sources corresponded surprisingly well at around 2,000 operations per million general population.

\section{International Comparison- OECD Nations, Japan, Korea and US}

When compared with other European countries with advanced health care systems (OECD nations), the incidence rate of spine surgery in US is very high. ${ }^{17)}$ The US has by far the highest utilization rate for spine surgery. When compared with the US as $100 \%$, incidence of spinal surgery was $33 \%$ for Sweden, 44\% for Australia, 49\% for Ontario Canada and Norway, 56\% for Finland, and 64\% for Denmark (Table 2). The variation was not correlated with the density of neurosurgeons and orthopedic surgeons in each country.

Japan has a prototypical system of socialized medicine. The national health insurance system was restructured in the post-war order under the auspices of the General Headquarters staffed by the delegates of then Truman administration. The Japanese national health care system encompasses compulsory and universal enrollment and allows its enrollees access to any medical institution in the country. The insurance system provides reimbursement following unified schedules for procedures, and the coverage is $70 \%(90 \%$ if age older than 75 years) for medical and surgical treatments and basic hospital fees.

Statistics of spine surgical procedures are gathered by the Japanese Society of Spinal Surgery, a neurosurgical organization, and the Japanese Society for Spine Surgery and Related Research, an orthopedic organization. Both surveys were based on questionnaires with somewhat limited enrollment (77-62\%). Neurosurgeons reported $13,000+$ spine procedures in 2004 ${ }^{75}$ and orthopedic surgeons reported $16,000+$ cases in $2001 .^{60)}$ Fifty-three percent of the cases treated by neurosurgeons were cervical cases and $20 \%$ for orthopedic surgeons. Another registration survey gathered annually by a

Table 2 Nation variety in utilization of spine surgery

$\begin{array}{ll}\text { USA } & 1.0 \\ \text { Japan } & 0.20-0.36 \\ \text { Korea } & 0.82-0.90 \\ \text { England } & 0.19 \\ \text { Sweden } & 0.33 \\ \text { Australia } & 0.44 \\ \text { Ontario, Canada } & 0.49 \\ \text { Norway } & 0.49\end{array}$

group of hospitals in a north-eastern region, an affiliation to a national university, reported $2900+$ cases for 4 million populations in 2007.48) In total, the annual number of spinal surgeries in Japan is estimated to be in the range of $400+$ to 725 per million population/yr, roughly $20 \%$ to $36 \%$ of the incidence in USA (Tables 1 and 2).

In Korea, the national health insurance system has a similar basic structure to Japan, with compulsory enrollment (97\%) and covering $80 \%$ of the hospital charges. The racial characteristics are very close to Japanese. Per capita public expenditure for medical care is approximately $30 \%$ of Japan ( $\$ 496$ vs $\$ 1,672$ in 2001 , GDP $\$ 19,274$ vs $\$ 28,395$ in 2003 ) and reimbursement for neurosurgical procedures is roughly one tenth of Japan as compared with purchasing power parity. There is a remarkable difference in the utilization pattern of spinal procedures between the two societies. Based on the statistics released by the Ministry of Health Welfare and Family Affairs of Korea, 80,318 spine procedures were performed for 49.1 million people in 2005 , with a 3 -fold increase in five years. ${ }^{26)}$ The per capita number of spine surgery is 1,630 per million/yr, which is nearly $80 \%$ of the US, with the proportion of fusion surgery using instrumentation higher than Japan (Table 1).

\section{Demand and Supply}

Adequate supply of spine surgeons should be inferred from two sets of numbers; the incidence of spine surgery, and adequate caseloads for a surgeon to maintain proficiency. We can only discuss these points in an arbitrary fashion, but in view of the diversity of complex pathologies that spine surgeons are facing in practice, probably 100 to 200 cases per year would be a practical case load, depending on the degree and proportion of complex lesions. Assuming the need for spine procedure of 1,000 cases per year per million, and surgeon's load of 100-200 procedures per year, the balanced supply would be 5-10 surgeons per million general population. Assuming 20 years of activity after completion of training, the matched annual production rate would be $0.25-0.5$ spine surgeons (trainee) per million population.

\section{Conclusion}

With entrepreneurial enthusiasm, implants have been strategically designed following market analysis and with intention of ease of use to attain success in the market. Corporate incentives and physicians' drive for financial or non-financial benefit are not always submerged behind the development. ${ }^{1)}$ These trends are affecting surgeons' behavior in judgment of indication and selection of approaches, and use of instruments to various degrees in different countries with different medico-socioeconomic conditions. The disparity is occasionally raising ethical ques- 
tions. ${ }^{73)}$ We find the structure of the health care/insurance system and the policy of reimbursement are critical in determining the behaviors of spine surgeons and can influence the directions of technological development. Reviewing the per capita incidence of spine surgery (and rate of instrumentation), the US has the highest rate, and certainly the rate of fixation among the procedures is high.

In Japan, the incidence of spine surgery is much lower at about one sixth to one third of that in the US. In Korea, the number of spine procedures per capita amounts to $80 \%$ of that in the US. The stark difference in the utilization of spine procedures in general and in instrumentation surgery between these two countries sharing similar national health insurance systems and comparable demographic characteristics, appears to be accountable only by the large gap in their reimbursement pricing policy. The low reimbursement in Korea results in much less per capita public medical expenditure, but may make the hospital financial and surgeon behavior sensitive to the influences promoting the provision of the implants. Such disparity in conditions influences the choice of surgical methods and may underlie the variations in the entire "culture" of spine surgery in these societies.

\section{References}

1) Abelson R: The spine as profit center. New York Times December 30, 2006. Available from: http://www.nytimes.com/ 2006/12/30/business/30spine.html?scp $=1 \& \mathrm{sq}=$ The + spine + as + profit + center\&st $=$ nyt

2) Abumi K, Kaneda K: Pedicle screw fixation for nontraumatic lesions of the cervical spine. Spine (Phila Pa 1976) 22: 1853-1863, 1997

3) Ames CP, Acosta FL Jr, Chi J, Iyengar J, Muiru W, Acaroglu E, Puttlitz CM: Biomechanical comparison of posterior lumbar interbody fusion and transforaminal lumbar interbody fusion performed at 1 and 2 levels. Spine (Phila Pa 1976) 30: E562-566, 2005

4) Apfelbaum RI: Caspar plating of the cervical spine, in Camins MB, O'Leary PF (eds): Disorders of the Cervical Spine. Baltimore, Md, Williams \& Wilkins, 1992, pp 593-601

5) Asher MA,Strippen WE, Hening CF, Carson WL: ISOLA spinal implant system: Principles, design, and applications, in An HS,Cother JM(eds): Spinal Instrumentation. Baltimore, Williams \& Wilkins, 1992,pp 325-351

6) Backes WH, Nijenhuis RJ: Advances in spinal cord MR angiography. AJNR Am J Neuroradiol 29: 619-631, 2008

7) Bartels RH, Donk RD, Pavlov P, van Limbeek J: Comparison of biomechanical properties of cervical artificial disc prosthesis: a review. Clin Neurol Neurosurg 110: 963-967, 2008

8) Benzel EC: Cervical disc arthroplasty compared with allograft fusion. J Neurosurg Spine 6: 197, 2007

9) Berger L: A surplus of treatment options, few of them good. New York Times August 30, 2007. Available from: http://health.nytimes.com/ref/health/healthguide/esnbackpain-ess.html

10) Blume HG, Rojas CH: Unilateral lumbar interbody fusion (posterior approach) utilizing dowel graft. Journal of Neurological and Orthopaetic Medicine and Surgery 2: 171-175, 1981

11) Boden SD, Balderston RA, Heller JG, Hanley EN Jr, Zigler JE: An AOA critical issue. Disc replacements: this time will we really cure low-back and neck pain? J Bone Joint Surg Am 86-A: 411-422, 2004
12) Boden SD, Davis DO, Dina TS, Patrons NJ, Wiesel SW: Abnormal magnetic-resonance scans of the lumbar spine in asymptomatic subjects. A prospective investigation. J Bone Joint Surg Am 72: 403-408, 1990

13) Böhler J: Anterior stabilization for acute fractures and nonunions of the dens. J Bone Joint Surg Am 64: 18-27, 1982

14) Boll DT, Bulow H, Blackham KA, Aschoff AJ, Schmitz BL: MDCT angiography of the spinal vasculature and the artery of Adamkiewicz. AJR Am J Roentgenol 187: 1054-1060, 2006

15) Callahan RA, Johnson RM, Margolis RN, Keggi KJ, Albright JA, Southwick WO: Cervical facet fusion for control of instability following laminectomy. J Bone Joint Surg Am 59: 991-1002, 1977

16) Caspar W, Barbier DD, Klara PM: Anterior cervical fusion and Caspar plate stabilization for cervical trauma. Neurosurgery 25: 491-502, 1989

17) Cherkin DC, Deyo RA, Loeser JD, Bush T, Waddell G: An international comparison of back surgery rates. Spine 19: 1201-1206, 1994

18) Cloward RB: The treatment of ruptured lumbar intervertebral discs by vertebral body fusion. I. Indications, operative technique, aftercare. J Neurosurg 10: 154-168, 1953

19) Cooper PR, Cohen A, Rosiello A, Koslow M: Posterior stabilization of cervical spine fractures and subluxations using plates and screws. Neurosurgery 23: 300-306, 1988

20) Cotrel Y, Dubousset J: Nouvelle technique d'osteosynthese rachidienne segmentaire voie posterieure. Rev Chir Orthop Reparatrice Appar Mot 70: 489-494, 1984 (French)

21) Craig Humphreys, S. Hodges, Scott D. Patwardhan, Avinash G. Eck, Jason C. Bryan Murphy, R. Covington, Laurie A: Comparison of posterior and transforaminal approaches to lumbar interbody fusion. Spine 26: 567-571, 2001

22) Deyo RA, Gray DT, Kreuter W, Mirza S, Martin BI: United States trends in lumbar fusion surgery for degenerative conditions. Spine (Phila Pa 1976) 30: 1441-1447, 2005

23) Deyo RA, Mirza SK, Martin BI, Kreuter W, Goodman DC, Jarvik JG: Trends, major medical complications, and charges associated with surgery for lumbar spinal stenosis in older adults. JAMA 303: 1259-1265, 2010

24) Deyo RA, Nachemson A, Mirza SK: Spinal-fusion surgery-the case for restraint. N Engl J Med 350: 722-726, 2004

25) Ebraheim NA, An HS, XU R: The quantitative anatomy of the cervical nerve root groove and the intervertebral foramen. Spine (Phila Pa 1976) 21: 1619-1623, 1996

26) Eoh W: Current status in Korean spine surgeons: Satellite Symposium Lecture. The 6th Biennial Korea-Japan Conference on Spinal Surgery. Busan, Korea, March 29-31, 2007

27) Freeman BJ, Davenport J: Total disc replacement in the lumbar spine: a systematic review of the literature. Eur Spine J 15 Suppl 3: S439-447, 2006

28) Geisler FH: The CHARITE Artificial Disc: design history, FDA IDE study results, and surgical technique. Clin Neurosurg 53: 223-228, 2006

29) Gluf WM, Schmidt MH, Apfelbaum RI: Atlantoaxial transarticular screw fixation: a review of surgical indications, fusion rate, complications and lessons learned in 191 adult patients. J Neurosurg Spine 2: 155-163, 2005

30) Goel A, Desai KI, Muzumdar DP: Atlantoaxial fixation using place and screw method; a report of 160 treated patients. Neurosurgery 51: 1351-1356, 2002

31) Grams AE, Gempt J, Forschler A: Comparison of spinal anatomy between 3-Tesla MRI and CT-myelography under healthy and pathological conditions. Surg Radiol Anat 32: 581-585, 2010

32) Gray DT, Deyo RA, Kreuter W, Mirza SK, Heagerty PJ, Comstock BA, Chan L: Population-based trends in volumes and rates of ambulatory lumbar spine surgery. Spine (Phila $\mathrm{Pa}$ 1976) 31: 1957-1964, 2006

33) Harms J, Melcher RP: Posterior C1-C2 fusion with polyaxial screw and rod fixation. Spine (Phila Pa 1976) 26: 2467-2471, 2001

34) Harms JG, Jeszenszky D: The unilateral, transforaminal approach for posterior lumbar interbody fusion. Orthop Traumatol 6: 88-99, 1998

35) Harrington PR: Treatment of scoliosis. Correction and inter- 
nal fixation by spine instrumentation. J Bone Joint Surg Am 44-A: 591-610, 1962

36) Hasegawa T, Mikawa Y, Watanabe R: Morphometric analysis of the lumbosacral nerve roots and dorsal root ganglia by magnetic resonance imaging. Spine 21: 1005-1009, 1996

37) Heidecke V, Rainov NG, Burkert W: Anterior cervical fusion with the Orion locking plate system. Spine (Phila Pa 1976) 23: 1796-1803, 1998

38) Hida K, Iwasaki Y, Yano S, Akino M, Seki T: Long-term follow-up results in patients with cervical disk disease treated by cervical anterior fusion using titanium cage implants. Neurol Med Chir (Tokyo) 48: 440-446,2008

39) Hiroshima K, Suzuki M, Namiki H: [Histopathological changes of the human spinal cord-with special reference to latent lesions found in spinal cords of the aged]. Nippon Seikeigeka Gakkai Zasshi 57: 729-739, 1983 (Japanese)

40) Hyodoh H, Kawaharada N, Akiba H, Tamakawa M, Hyodoh K, Fukada J, Morishita K, Hareyama M: Usefulness of preoperative detection of artery of Adamkiewicz with dynamic contrast-enhanced MR angiography. Radiology 236: 1004-1009, 2005

41) Imai T: [Cervical spondylotic myelopathy and the anteroposterior diameter of the cervical canal]. Nippon Seikeigeka Gakkai Zasshi 44: 429-438, 1970 (Japanese)

42) Irwin ZN, Hilibrand A, Gustavel M, McLain R, Shaffer W, Myers M, Glaser J, Hart RA: Variation in surgical decision making for degenerative spinal disorders. Part I: lumbar spine. Spine (Phila Pa 1976) 30: 2208-2213, 2005

43) Jeanneret B, Magerl F: Primary posterior fusion C1/2 in odontoid fractures: indications, technique, and results of transarticular screw fixation. J Spinal Disord 5: 464-475, 1992

44) Johnston CE II, Herring JA, Ashman RB: Texas Scottish Rite Hospital(TSRH) universal spinal instrumentation, in An HS,Cother JM (eds): Spinal Instrumentation. Baltimore, Williams \& Wilkins, 1992,pp 127-166

45) Kim P, Murata H, Kurokawa R, Takaishi Y, Asakuno K, Kawamoto T: Myoarchitectonic spinolaminoplasty: efficacy in reconstituting the cervical musculature and preserving biomechanical function. J Neurosurg Spine 7: 293-301, 2007

46) Kotani Y, Abumi K, Ito M, Minami A: Improved accuracy of computer-assisted cervical pedicle screw insertion. J Neurosurg 99(3 Suppl): 257-263, 2003

47) Krinsky G, Rofsky NM, Weinreb JC: Nonspecificity of short inversion time invesion recovery (STIR) as a technique of fat suppression: pitfalls in image interpretation. AJR Am J Roentgenol 166: 523-526, 1996

48) Kusakabe T, Ozawa K, Idoi E, Matsumoto F, Tanaka Y, Ishii H, Kokubun S, Sato T: [Report of Tohoku University Group Spine Surgery Registry]. Tohoku Seikei Saigai Geka Gakkaishi 54: 134, 2010 (Japanese)

49) Lafuente J, Casey AT, Petzold A, Brew S: The Bryan cervical disc prosthesis as an alternative to arthrodesis in the treatment of cervical spondylosis: 46 consecutive cases. J Bone Joint Surg Br 87: 508-512, 2005

50) Le Bihan D, Mangin JF, Poupon C: Diffusion tensor imaging concepts and applications. J Mang Reson Imiaging 13: 534-546, 2001

51) Luque ER, Cassis N, Ramirez-Wiella G: Segmental spinal instrumentation in the treatment of fractures of the thoracolumbar spine. Spine (Phila Pa 1976) 7: 312-317, 1982

52) Magerl F, Seeman PS: Stable posterior fusion of the atlas and axis by transarticular screw fixation, in Kehr P, Werdner PA (eds): Cervical Spine I. Vienna, Springer, 1987, pp 322-327

53) Maier SE, Mamata H: Diffusion tensor imaging of the spinal cord. Ann N Y Acad Sci 1064: 50-60, 2005

54) Masutani Y, Aoki S, Abe O, Hayashi N, Otomo K: MR diffusion tensor imaging: recent advance and new techniques for diffusion tensor visualization. Eur J Radiol 46: 53-66, 2003

55) Matsumoto M, Fujimura Y, Suzuki N, Nishi Y, Nakamura M, Yabe Y, Shiga H: MRI of cervical intervertebral discs in asymptomatic subjects. J Bone Joint Surg Br 80: 19-24,1998

56) Mendenhall Associates, Inc.: 2002 Spinal industry update. Orthopedic Network News 13(4): 7-8, 2002

57) Mull M, Nijenguis RJ, Backes WH, Krings T, Wilmink JT,
Thron A: Value and limitations of contrast-enhanced MR angiography in spinal arteriovenous malformations and dural arteriovenous fistulas. AJNR Am J Neuroradiol 28: 12491258, 2007

58) Mummaneni PV, Haid RW, Rodts GE: Lumbar interbody fusion: state-of-the-art technical advances. Invited submission from the Joint Section Meeting on Disorders of the Spine and Peripheral Nerves. J Neurosurg Spine 1: 24-30, 2004

59) Nagayama M, Watanabe $Y$, Okumura A, Amoh Y, Nakashita S, Dodo Y: High-resolution single-slice MR myelography. AJR Am J Roentgenol 179: 515-521, 2002

60) Nohara Y, Taneichi H, Ueyama K, Kawahara N, Shiba K, Tokuhashi Y, Tani T, Nakahara S, Iida T: Nationwide survey on complications of spine surgery in Japan. J Orthop Sci 9: 424-433, 2004

61) Opepelt A, Graumann R, Barfuss H: FISP: a new fast MRI sequence. Electroedica 54: 15-18, 1986

62) Rabin RC: Procedures: Sharp rise in complex back surgery among older adults. New York Times April 9, 2010. Available from: http://www.nytimes.com/2010/04/13/health/research/ 13proc.html

63) Ray CD: Threaded titanium cages for lumbar interbody fusions. Spine (Phila Pa 1976) 22: 667-680, 1997

64) Roy-Camile R, Saillant G, Mazel C: Internal fixation of the lumbar spine with pedicle screw plating. Clin Orthop Relat Res (203): 7-17, 1986

65) Seichi A, Takeshita K, Nakajima S, Akune T, Kawaguchi H, Nakamura K: Revision cervical spine surgery using transarticular or pedicle screws under a computer-assisted imageguidance system. J Orthop Sci 10: 385-390, 2005

66) Shapiro MD: MR imaging of the spine at 3T. Magn Reson Imaging Clin N Am 14: 97-108, 2006

67) Steffee AD, Biscup RS, Sitkowski DJ: Segmental spine plates with pedicle screw fixation. A new internal fixation device for disorders of the lumbar and thoracolumbar spine. Clin Orthop Relat Res (203): 45-53, 1986

68) Takayasu M, Hara M, Yamauchi K, Yoshida M, Yoshida J: Transarticular screw fixation in the middle and lower cervical spine. Technical note. J Neurosurg 99(1 Suppl): 132-136, 2003

69) Teresi LM, Lufkin RB, Reicher MA, Moffit BJ, Vinuela FV, Wilson GM, Bentson JR, Hanafee WN: Asymptomatic degenerative disk disease and spondylosis of the cervical spine: MR Imaging. Radiology 164: 83-88,1987

70) Voor MJ, Mehta S, Wang M, Zhang YM, Mahan J, Johnson JR: Biomechanical evaluation of posterior and anterior lumbar interbody fusion techniques. J Spinal Disord 11: 328-334, 1998

71) Weinstein JN, Lurie JD, Olson PR, Bronner KK, Fisher ES: United States' trends and regional variations in lumbar spine surgery: 1992-2003. Spine (Phila Pa 1976) 31: 27072714, 2006

72) Weinstein JN, Tosteson TD, Lurie JD, Tosteson AN, Blood E, Hanscom B, Herkowitz H, Cammisa F, Albert T, Boden SD, Hilibrand A, Goldberg H, Berven S, An H; SPORT Investigators: Surgical versus nonsurgical therapy for lumbar spinal stenosis. N Engl J Med 358: 794-810, 2008

73) Wenger DR: Spine surgery at a crossroads: does economic growth threaten our professionalism?. Spine (Phila Pa 1976) 32: 2158-2165, 2007

74) Wiltse L: History of pedicle screw fixation of the spine, in: Spine: State of the Art Reviews, vol 6. Philadelphia, Hanley \& Belfus, 1992, pp 1-10

75) Yano S, Hida K, Iwasaki Y: [Nationwide analysis of spinal surgery by Japanese neurosurgeons-Report of the results for survey questionanaires in 2004]. Sekizui Geka 19: 299-305, 2005 (Japanese)

76) Yoon DH, Yi S, Shin HC, Kim KN, Kim SH: Clinical and radiological results following cervical arthroplasty. Acta Neurochir (Wien) 148: 943-950, 2006

Address reprint requests to: Phyo Kim, M.D., Neurologic Surgery, Dokkyo University School of Medicine, $880 \mathrm{Mibu}$, Shimotsuga-gun, Tochigi 321-0293, Japan. e-mail: kim@dokkyomed.ac.jp 